MOREIRA, M.A.; FONTES, PC.R.; FONTES, R.L.F.; CARDOSO, A.A. Crescimento e produtividade da batateira, em função do modo de aplicação do fertilizante e dos fungicidas contendo Zn. Horticultura Brasileira, Brasília, v. 18, n. 1, p.72-76, março 2.000

\title{
Crescimento e produtividade da batateira, em função do modo de apli- cação do fertilizante e dos fungicidas contendo $\mathrm{Zn}$.
}

\author{
Marialva A. Moreira ${ }^{1}$; Paulo C. R. Fontes ${ }^{2}$; Renildes L. F. Fontes ${ }^{3}$; Antônio A. Cardoso ${ }^{4}$. \\ ${ }^{1}$ Mestranda UFV, Depto. Fitotecnia, ${ }^{2,4}$ Bolsistas do CNPq, UFV, ${ }^{3}$ UFV, DPS 36.571-000 Viçosa-MG.
}

\begin{abstract}
RESUMO
O presente trabalho teve por objetivo avaliar os efeitos do modo de aplicação do fertilizante contendo $\mathrm{Zn}$ e de fungicidas contendo ou não $\mathrm{Zn}$ sobre o crescimento, a produtividade e o conteúdo de nutrientes dos tubérculos de batata. $\mathrm{O}$ experimento foi conduzido na Horta Nova, da Universidade Federal de Viçosa, com a cultivar Monalisa, em solo Podzólico Vermelho - Amarelo Câmbico, contendo $6,9 \mathrm{mg} \mathrm{dm}^{-3} \mathrm{de} \mathrm{Zn}^{+2}$, extraído por Mehlich-1. O delineamento experimental foi o de blocos casualizados em parcelas subdivididas, com quatro repetições. Nas parcelas avaliou-se os efeitos da aplicação de fungicidas (contendo ou não $\mathrm{Zn}$ ) e nas subparcelas o modo de aplicação do fertilizante contendo $\mathrm{Zn}$ (testemunha, $\mathrm{Zn}$ aplicado no solo, $\mathrm{Zn}$ pulverizado na parte aérea da planta e $\mathrm{Zn}$ no solo + parte aérea). O crescimento da planta, representado pelo comprimento e número de caules, peso da matéria seca da parte aérea e número de tubérculos, foi caraterizado aos 20 e 45 dias após a sua emergência. Após a senescência natural das plantas, os tubérculos foram colhidos, classificados e pesados. Em ambas as épocas de amostragens, os tratamentos não influenciaram o crescimento da batateira. A produtividade de tubérculos comerciais $(44,2 \mathrm{t} / \mathrm{ha})$ foi maior na parcela em que as plantas foram pulverizadas com fungicidas contendo zinco e não foi influenciada pelo modo de fertilização. Os tratamentos não apresentaram efeito sobre os conteúdos de $\mathrm{P}, \mathrm{Ca}, \mathrm{Mg}, \mathrm{Cu}$ e Fe nos tubérculos; porém, os conteúdos de $\mathrm{Mn}$ e $\mathrm{Zn}$ foram maiores quando as plantas foram pulverizadas com fungicidas contendo $\mathrm{Zn}$.
\end{abstract}

Palavras-chave: Solanum tuberosum, micronutriente, pulverização foliar, adubação.

\begin{abstract}
Potato plant growth and tuber yield as a function of $\mathrm{Zn}$ fertilizer application methods and $\mathrm{Zn}$ fungicides.

The objective of the experiment was to evaluate the effects of $\mathrm{Zn}$ fertilizer application methods and fungicides with or without $\mathrm{Zn}$ on potato plant growth, tuber yield and nutrient contents. The experiment was installed in the Horta Nova of the Universidade Federal de Viçosa with the Monalisa cultivar on a cambic Red-yellow Podzolic, containing $6.9 \mathrm{mg} \mathrm{dm}^{-3}$ of $\mathrm{Zn}$ extracted by Mehlich-1. The experiment was carried out in a randomized block design with four replications in a split plot design. The fungicide spray programs (with or without $\mathrm{Zn}$ ) were done in the main plots and the zinc fertilizer application methods (control, $\mathrm{Zn}$ in the soil, $\mathrm{Zn}$ sprayed on the plant shoots and $\mathrm{Zn}$ in soil + shoots) were in the split plots. Plant growth (stem lengths and numbers, shoot dry matter and tuber numbers) was characterized at 20 and 45 days after plant emergence. Following natural senescence, tubers were harvested, graded and weighted. At both sampling dates, plant growth was not affected by the treatments. Commercial tuber yield (44.2 t/ha) was higher in the plots receiving fungicides containing $\mathrm{Zn}$ and it was not affected by zinc fertilizer application methods. The treatments did not affect the $\mathrm{P}, \mathrm{Ca}, \mathrm{Mg}$, $\mathrm{Cu}$ and $\mathrm{Fe}$ contents in the tubers but $\mathrm{Mn}$ and $\mathrm{Zn}$ contents were higher when plants were sprayed with $\mathrm{Zn}$ fungicides.
\end{abstract}

Keywords: Solanum tuberosum, micronutrient, foliar sprays, soil application.

(Aceito para publicação em 20 de janeiro de 2.000)

$\mathrm{E}^{\mathrm{n}}$ m solos tropicais, uma das limitações ao desenvolvimento e à produtividade da batateira é a baixa disponibilidade de fósforo. Como consequência, aumentos de produtividades quase sempre ocorrem quando o solo recebe elevada quantidade de adubo fosfatado (Fontes et al.,1997). Porém, o uso de altas doses de adubo fosfatado pode induzir ou aumentar a deficiência de zinco em plantas, particularmente em condições de limitada disponibilidade deste ion (Cakmak \& Marschner, 1987) e de temperaturas abaixo de $15^{\circ} \mathrm{C}$, (Martin et al.,1965).

Em solo cujo teor de $\mathrm{Zn}$ foi considerado moderamente baixo $(0,90 \mathrm{mg}$ $\mathrm{dm}^{-3}$ de $\mathrm{Zn}^{+2}$ extraído com ditizona),
Martin et al. (1965) mostraram que aconteceu em condições de baixa temperatura a adição de alta dose de $\mathrm{P}$ (200 mg $\mathrm{dm}^{-3}$ ) induziu à deficiência de $\mathrm{Zn}$ em tomate. Este efeito não se verificou em temperatura do solo acima de $21^{0} \mathrm{C}$. Porém, em solo com teor muito baixo de zinco $\left(0,10 \mathrm{mg} \mathrm{dm}^{-3}\right)$, as plantas adubadas com fósforo apresentaram deficiência de $\mathrm{Zn}$, independemente da temperatura.

A deficiência de zinco aumenta a permeabilidade das membranas radiculares (Marschner, 1995) e pode contribuir para a excessiva absorção de fósforo (Marschner \& Cakmak, 1986; Parker, 1997). Assim, foi verificado que plantas de batata deficientes em zinco apresentavam altas concentrações de fósforo em seus tecidos (Christensen \& Jackson, 1981). Os sintomas de deficiência de zinco mais comumente apresentados pela batateira são caracterizados pela posição quase vertical das folhas do ápice da planta, com as margens dos folíolos voltando-se para cima (Fontes, 1987) e por má formação das folhas, bronzeamento ou amarelecimento presentes ao redor das margens das folhas jovens (Boawn \& Leggett, 1963).

A deficiência de zinco pode ser corrigida pela sua adição ao solo, em quantidades variando de 4 a $35 \mathrm{~kg} / \mathrm{ha}$ (Martens \& Westermann,1991). Entretanto, a absorção do zinco pelas raízes, especialmente em solos intemperizados e com altos teores de óxidos de ferro e 
alumínio pode ser prejudicada pela ação adsortiva exercida por eles sobre o zinco adicionado (Saeed \& Fox, 1979). Além disto, a disponibilidade de zinco pode também ser reduzida pela elevação do $\mathrm{pH}$, decorrente da calagem, tornando a sua aplicação via foliar uma possível alternativa. Usualmente, quando suplementado por via foliar, o zinco é aplicado em quantidade em torno de 0,5 kg ha-1 (Volkweiss, 1991; Yilmaz et al., 1997).

Diferentes métodos de aplicação do fertilizante contendo zinco e a sua presença nos fungicidas normalmente aplicados à cultura promoveram aumento no teor de zinco na parte aérea da batateira (Moreira, 1998). Entretanto, em condições brasileiras, pouco é sabido sobre os efeitos dos métodos de aplicação do fertilizante contendo zinco sobre a produtividade da cultura. Ainda mais que o efeito do zinco adicionado como fertilizante pode estar sendo confundido com aquele presente nos fungicidas, normalmente aplicados à cultura da batata. Assim, o presente trabalho teve como objetivo avaliar os efeitos do modo de aplicação do fertilizante contendo $\mathrm{Zn}$ e de fungicidas contendo ou não $\mathrm{Zn}$ sobre o crescimento, a produtividade e o conteúdo de nutrientes dos tubérculos de batata.

\section{MATERIAL E MÉTODOS}

Foi conduzido um experimento na Horta Nova, no campus da Universidade Federal de Viçosa, em solo Podzólico Vermelho-amarelo câmbico, contendo $38 \%$ de argila, $\mathrm{pH}\left(\mathrm{H}_{2} \mathrm{O}\right)$ igual a $6,0, \mathrm{com}$ os teores iniciais de 93 e $6,9 \mathrm{mg} . \mathrm{dm}^{-3} \mathrm{de}$ $\mathrm{P}$ e $\mathrm{Zn}^{+2}$, extraídos por Mehlich-1.

O delineamento experimental utilizado foi o de blocos casualizados em parcelas subdivididas, com quatro repetições. Nas duas parcelas foram aplicados os fungicidas (contendo ou não $\mathrm{Zn}$ ) e nas quatro subparcelas, testou-se o modo de aplicação do fertilizante contendo $\mathrm{Zn}$ (testemunha, $\mathrm{Zn}$ aplicado no solo, $\mathrm{Zn}$ pulverizado na parte aérea e Zn solo + parte aérea). Cada parcela experimental foi constituída de quatro fileiras de 10 plantas, no espaçamento de $0,8 \times 0,3 \mathrm{~m}$. A área útil foi constituída pelas duas fi-

Tabela 1. Programa semanal de pulverizações com fungicidas contendo ou não zinco em suas formulações. Viçosa, UFV, 1997.

\begin{tabular}{lll}
\hline \multirow{2}{*}{ Semana } & \multicolumn{2}{c}{ Programas de pulverizações com fungicidas } \\
\cline { 2 - 3 } & \multicolumn{1}{c}{ Com zinco } & \multicolumn{1}{c}{ Sem zinco } \\
\hline 1 & Mancozeb & Chlorothalonil \\
2 & Cymoxanil & Chlorothalonil \\
3 & Mancozeb & Chlorothalonil \\
4 & Mancozeb + Metalaxyl & Metalaxyl \\
5 & Mancozeb & Chlorothalonil \\
6 & Mancozeb + Metalaxyl & Metalaxyl \\
7 & Oxicloreto de Cobre & Oxicloreto de Cobre \\
\hline
\end{tabular}

leiras centrais, eliminando-se a primeira planta de ambas as extremidades.

Os programas de pulverização com fungicidas contendo ou não $\mathrm{Zn}$ estão na Tabela 1, tendo sido empregados nas dosagens recomendadas pelos fabricantes. Foram feitas sete pulverizações com os fungicidas, sendo a primeira sete dias após a emergência (DAE) e as subsequentes semanalmente. $\mathrm{O}$ total de $\mathrm{Zn}$ aplicado como fungicida foi $3,6 \mathrm{mg}$ por planta.

No tratamento $\mathrm{Zn}$ no solo, este foi colocado nos sulcos, por ocasião do plantio, na dosagem de $4 \mathrm{~kg} / \mathrm{ha}$, utilizando-se o sulfato de zinco. Nas aplicações foliares foi utilizada uma solução contendo $0,5 \mathrm{~g} / \mathrm{L}$ de $\mathrm{Zn}$, na forma de sulfato de zinco, aos 20 e 45 dias após a emergência (DAE). Foram gastos, em média, 11,4 e $12,2 \mathrm{~mL} /$ planta de solução, respectivamente.

O plantio dos tubérculos foi feito em julho de 1997, utilizando-se a cultivar Monalisa. A adubação, feita nos sulcos, constou de 300 de sulfato de amônio, 1.400 de superfosfato triplo e 500 de cloreto de potássio, 200 de sulfato de magnésio e 15 de bórax, todos expressos em $\mathrm{kg} / \mathrm{ha}$. A amontoa foi realizada aos 15 DAE, por ocasião da adubação nitrogenada em cobertura com $600 \mathrm{~kg} /$ ha de sulfato de amônio.

Aos 20 e 45 DAE, antes da aplicação foliar do $\mathrm{Zn}$, foram realizadas amostragens de planta inteira, caracterizandose o crescimento (comprimento e número de caule, peso da matéria seca da parte aérea e número de tubérculos).

A colheita dos tubérculos foi realizada em 23 de outubro de 1997, após a secagem completa da parte aérea. Os tubérculos foram classificados em comerciais e não comerciais. Os tubérculos não comerciais foram avaliados quanto ao embonecamento, coração oco, rachadura e esverdeamento. Os tubérculos comerciais foram classificados de acordo com o seu maior diâmetro transversal em: classe $1=\emptyset^{3} 8,5 \mathrm{~cm}$; classe 2 $=4,5 \mathrm{~cm}<\varnothing<8,4 \mathrm{~cm}$; classe $3=3,3 \mathrm{~cm}$ $<\varnothing<4,4 \mathrm{~cm}$ e classe $4=\varnothing<3,3 \mathrm{~cm}$, com base na Portaria número 69 de 21/02/95 do Ministério da Agricultura e Reforma Agrária. Os tubérculos foram avaliados também quanto ao teor de matéria seca, $\mathrm{P}, \mathrm{Ca}, \mathrm{Mg}, \mathrm{Cu}, \mathrm{Fe}, \mathrm{Mn}$ e $\mathrm{Zn}$. Os dados obtidos foram submetidos à análise de variância.

\section{RESULTADOS E DISCUSSÃO}

Comprimento do caule, número de caules e número de tubérculos

O comprimento e o número de caules, e o número de tubérculos, avaliados aos 20 e 45 dias após a emergência (DAE), não foram significativamente afetados pelo uso de fungicidas contendo zinco e nem pelo modo de aplicação do fertilizante, não havendo também interação significativa entre eles. $\mathrm{Na}$ média de todos os tratamentos, os comprimentos dos caules foram 46 e $60 \mathrm{~cm}$, aos 20 e 45 DAE, respectivamente. Reis Jr. (1995), testando a cultivar Baraka, aos 48 DAE, encontrou associação entre a máxima produção classificada de tubérculos e o comprimento de caule. Do mesmo modo, Rocha (1995) observou que os comprimentos do caule de 55 e $70 \mathrm{~cm}$, tanto aos 20 como aos 50 DAE, estavam associados à máxima produtividade de tubérculos da cultivar Baraka. 
Tabela 2. Conteúdos de $\mathrm{P}, \mathrm{Ca}, \mathrm{Mg}, \mathrm{Cu}, \mathrm{Fe}, \mathrm{Mn}$ e $\mathrm{Zn}$ nos tubérculos de batata, em função do uso de fungicidas contendo ou não Zn e do modo de fertilização com Zn. Viçosa, UFV, 1997.

\begin{tabular}{|c|c|c|c|c|c|c|c|c|}
\hline \multirow{2}{*}{ Fungicida } & \multirow{2}{*}{$\begin{array}{l}\text { Modo de } \\
\text { Aplicação }\end{array}$} & \multicolumn{7}{|c|}{ Conteúdos de nutrientes } \\
\hline & & $\mathbf{P}$ & $\mathbf{C a}$ & Mg & $\mathrm{Cu}$ & $\mathrm{Fe}$ & Mn & $\mathrm{Zn}$ \\
\hline & & \multicolumn{3}{|c|}{ g planta $^{-1}$} & \multicolumn{4}{|c|}{ mg planta $^{-1}$} \\
\hline \multirow[t]{4}{*}{ Com Zn } & Testemunha & 0,49 & 0,074 & 0,21 & 1,10 & 9,48 & 2,18 & 3,34 \\
\hline & Solo & 0,50 & 0,078 & 0,25 & 1,30 & 9,53 & 2,43 & 3,63 \\
\hline & Foliar & 0,44 & 0,076 & 0,24 & 1,03 & 12,43 & 2,50 & 3,98 \\
\hline & Solo+Foliar & 0,48 & 0,082 & 0,24 & 1,03 & 7,93 & 2,15 & 4,11 \\
\hline \multirow[t]{4}{*}{ Sem Zn } & Testemunha & 0,50 & 0,084 & 0,24 & 1,00 & 11,25 & 1,68 & 3,09 \\
\hline & Solo & 0,47 & 0,080 & 0,25 & 0,98 & 9,25 & 1,80 & 2,99 \\
\hline & Foliar & 0,44 & 0,069 & 0,23 & 0,98 & 10,83 & 1,73 & 3,37 \\
\hline & Solo+Foliar & 0,47 & 0,076 & 0,21 & 0,98 & 10,03 & 1,58 & 3,64 \\
\hline Com Zn & $\bullet$ & 0,48 & 0,077 & 0,24 & 1,11 & 9,84 & $2,31 \mathrm{~A}$ & $3,77 \mathrm{~A}$ \\
\hline Sem Zn & $\bullet$ & 0,47 & 0,077 & 0,23 & 0,98 & 10,34 & $1,69 \mathrm{~B}$ & $3,27 \quad B$ \\
\hline$\bullet$ & Testemunha & 0,50 & 0,079 & 0,23 & 1,05 & 10,36 & 1,96 & 3,21 \\
\hline$\bullet$ & Solo & 0,48 & 0,079 & 0,25 & 1,14 & 9,39 & 2,11 & 3,31 \\
\hline$\bullet$ & Foliar & 0,44 & 0,073 & 0,23 & 1,00 & 11,63 & 2,11 & 3,68 \\
\hline - & Solo+Foliar & 0,48 & 0,078 & 0,23 & 1,00 & 8,98 & 1,86 & 3,87 \\
\hline
\end{tabular}

Letras maiúsculas comparam o uso de fungicidas contendo ou não zinco pelo teste $\mathrm{F}$ a $5 \%$ de probabilidade.

Aos 20 e 45 DAE, o número médio de caules por planta foi 3,6 e 3,8, correspondendo a 15 e 16 caules/m, respectivamente. Esta característica varia de acordo com diversos fatores, dentre os quais a cultivar (Morena et al.,1994). Beukema \& Van Der Zaag (1990) citam que para as condições européias são necessárias 15 a 20 hastes/m para produção adequada de batata para consumo, enquanto Fontes et al. (1995) mostraram que o número adequado de hastes por unidade de área depende da cultivar e do preço da batata semente.

O número médio de tubérculos por planta foi 14,0 e 13,3, aos 20 e 45 DAE, respectivamente. Portanto, já aos 20 DAE, os números de caules e de tubérculos por planta já estavam definidos. Este fato foi diferente do encontrado por Reis Jr. (1995), que verificou maior número de tubérculos da cultivar Baraka aos 48 do que aos 20 DAE.

\section{Produção de matéria seca}

A produção de matéria seca da parte aérea e dos tubérculos por planta não foi significativamente afetada pelos tratamentos. Aos 20 DAE, cada planta apresentou, como média dos tratamentos com fungicidas, as seguintes produções de matéria seca: $23,7 \mathrm{~g}$ de parte aérea e 10,5 $\mathrm{g}$ de tubérculos, enquanto que aos 45 DAE os valores médios foram: 29,5 e 110,3 g, respectivamente. Boawn \& Leggett (1964) não encontraram resposta da produção de matéria seca das folhas da batateira com adição de zinco no solo ou na solução nutritiva. Porém, Christensen \& Jackson (1981) verificaram que a produção de matéria seca das folhas das plantas cultivadas em solução nutritiva foi afetada pela interação zinco e fósforo na solução.

Conteúdos de nutrientes nos tubérculos

Os conteúdos de fósforo, cálcio, magnésio, cobre e ferro nos tubérculos não foram afetados pelos tratamentos (Tabela 2). Na média dos tratamentos pulverizados com fungicidas contendo zinco houve a retirada pelos tubérculos de $20 \mathrm{~kg}$ de $\mathrm{P}, 10 \mathrm{~kg}$ de $\mathrm{Mg}, 3.208 \mathrm{~g}$ de $\mathrm{Ca}, 410 \mathrm{~g}$ de $\mathrm{Fe}, 157 \mathrm{~g}$ de Zn, $97 \mathrm{~g}$ de $\mathrm{Mn}$ e $47 \mathrm{~g}$ de $\mathrm{Cu} / \mathrm{ha}$. A quantidade de nutrientes removida pelos tubérculos depende da produtividade e dos teores de nutrientes nos tubérculos, ambos variando com o solo, o ano, a adubação e a cultivar (Paula et al., 1986; Rocha, 1995). Por outro lado, os conteúdos de manganês e zinco nos tubérculos, elementos contidos nos fungicidas, foram afetados pelo uso de fungicidas contendo zinco (Tabela 2). Isto indica que a aplicação de fungicidas contendo zinco favoreceu a sua translocação para os tubérculos. Translocação do zinco aplicado nas folhas para as raízes e caules, de forma mais acentuada em plantas bem nutridas em zinco, foi observada em feijoeiro (Rodrigues et al., 1997).

As quantidades de zinco absorvidas pelos tubérculos, nos tratamentos da parcela cujas plantas receberam pulverizações com fungicida contendo zinco, foram 139, 151, 166 e $171 \mathrm{~g} / \mathrm{ha}$ para a testemunha, $\mathrm{Zn}$ no solo, $\mathrm{Zn}$ na parte aérea e Zn no solo + na parte aérea, respectivamente. Esses mesmos tratamentos receberam 241, 4.241, 734 e $4.584 \mathrm{~g} /$ ha de zinco, provenientes dos tubérculos plantados $(7,87 \mathrm{~g} / \mathrm{ha})$, do cloreto de potássio $(0,30 \mathrm{~g} / \mathrm{ha})$, do sulfato de amônio (0,24 g/ha), do calcário $(6,76$ $\mathrm{g} / \mathrm{ha})$, do superfosfato triplo $(21,0 \mathrm{~g} /$ ha), do sulfato de magnésio (55,0 g/ha), das pulverizações com fungicidas contendo zinco (150 g/ha) e dos tratamentos em que o zinco foi colocado no solo (4000 g/ha), pulverizado na parte aé- 
rea (493 g/ha) e no solo + parte aérea (4.493 g/ha).

Portanto, na parcela em que as plantas receberam pulverizações com fungicidas contendo zinco, as recuperações pelos tubérculos foram $0,30,0,71$ e 5,48\% do zinco aplicado no solo, aplicado no solo + parte aérea e pulverizado na parte aérea, respectivamente. Os valores correspondentes nas parcelas que receberam pulverizações com fungicidas não contendo zinco foram 0,$10 ; 0,51$ e 2,23 respectivamente. A baixa eficiência de recuperação do $\mathrm{Zn}$ adicionado como fertilizante pode ter sido devido à sua disponibilidade relativamente alta original no solo e a incorporação pelas diversas formas anteriormente mencionadas.

\section{Produtividade de tubérculos}

A utilização dos fungicidas contendo zinco, em comparação com aqueles que não o continham, proporcionou aumento significativo $(\mathrm{p} £ 0,05)$ na produtividade de tubérculos (Tabela 3). O uso de fungicidas contendo zinco proporcionou o mesmo efeito sobre o teor de zinco total na quarta folha da planta, determinado aos 20 DAE conforme os dados apresentados por Fontes et al. (1999).

As produtividades médias de tubérculos foram 44,2 e 40,1 t/ha com uso de fungicidas contendo ou não $\mathrm{Zn}$, respectivamente. Estes valores são considerados relativamente altos quando comparados com 22,14 t/ha, média da produtividade de países europeus, e 14,33 t/ ha, média brasileira (FAO, 1996). As produtividades alcançadas no presente ensaio foram devidas, em parte, à ausência aparente de doenças de folhagem durante todo o ciclo da batateira. A maior produtividade foi devido as aplicações de fungicidas contendo zinco. As aplicações do fungicida no estádio inicial de desenvolvimento da planta, período coincidente com temperaturas ainda baixas, podem ter favorecido a absorção de zinco através das folhas das plantas ainda jovens e com restrito sistema radicular. Nestas condições, a absorção de nutrientes é marcadamente reduzida, principalmente aqueles dependentes do processo de difusão, como é o caso do Zn. No milho, Leblanc et al. (1997) mostraram sintomas de deficiência de zinco mais acentuados em plantas jovens do

Tabela 3. Produção de tubérculos de batata (t/ha), em função do uso de fungicidas contendo ou não Zn e do modo de fertilização com Zn. Viçosa, DFT-UFV, 1997.

\begin{tabular}{lccc}
\hline \multirow{2}{*}{$\begin{array}{c}\text { Modo de aplicação } \\
\text { do fertilizante }\end{array}$} & \multicolumn{2}{c}{ Fungicida } & \multirow{2}{*}{ Média } \\
\cline { 2 - 3 } & Com Zn & Sem Zn & \\
\hline Testemunha & 42,0 & 42,3 & 42,2 a \\
Solo & 46,0 & 40,7 & 43,3 a \\
Foliar & 45,4 & 38,2 & 41,8 a \\
Solo+Foliar & 43,2 & 39,3 & 41,3 a \\
\hline Média & $44,2 \mathrm{~A}$ & $40,1 \mathrm{~B}$ & \\
\hline
\end{tabular}

Letras maiúsculas comparam o uso de fungicidas contendo ou não zinco e letras minúsculas comparam o modo de aplicação do fertilizante. Em cada coluna, as médias seguidas pela mesma letra maiúscula ou minúscula não expressam diferenças significativas a $5 \%$ de probabilidade pelos testes $\mathrm{F}$ e de Tukey, respectivamente.

que em plantas mais velhas, talvez, devido a diferenças no tamanho do sistema radicular. Ademais, o número de tubérculos e o número de caules já estavam definidos aos 20 DAE. Os fungicidas contendo zinco utilizados durante o experimento não foram analisados para saber se havia algum íon acompanhante que pudesse proporcionar esse aumento na produção de tubérculos.

No presente experimento não foi constatada a ocorrência de doenças na parte aérea da batateira em nenhum dos tratamentos, independentemente da aplicação ou não de Zn. Graham \& Webb (1991) mostram que o ion zinco pode ter nenhum efeito, decrescer ou aumentar a susceptibilidade das plantas a doenças. Estes autores, revisando a limitada literatura sobre o assunto, afirmam que a aplicação de zinco em quantidades maiores que aquelas necessárias para o crescimento das plantas, mas não fitotóxicas, podem ser benéficas na redução da manifestação de algumas doenças talvez pelo seu efeito tóxico sobre o patógeno ou pela sua importância na manutenção da integridade das biomembranas, principalmente das raízes. Entretanto, não há evidências do efeito de doses supraótimas de zinco na integridade e estabilidade das membranas. No tomateiro, em condições controladas, foi mostrado o efeito do zinco aumentando o biocontrole de Fusarium oxysporum por Pseudomonas fluorescens (Duffy \& Defago,1997).

O modo de aplicação do fertilizante não afetou significativamente a produtividade (Tabela 3), devido, provavelmente, ao teor de zinco no solo ter sido suficiente para o desenvolvimento da batateira. Ademais, houve aporte de zinco indiretamente pelos fertilizantes, calcários e tubérculo-semente. Ellis (1945) e Hoyman (1949) verificaram aumento na produtividade da batateira com o uso de zinco aplicado via foliar, mas não conseguiram resposta quando o zinco estava presente em quantidade suficiente no solo. Por outro lado, Boawn \& Leggett (1963) observaram que a aplicação de zinco via foliar não foi eficiente para remover os sintomas de sua deficiência na batateira, enquanto Grunes et al. (1961) verificaram aumento na produtividade da batateira com aplicação do zinco no solo.

Não ocorreu produção de tubérculos da classe 1. A única classe cuja produtividade respondeu significativamente ao uso de fungicidas contendo zinco foi a 2, que determinou a diferença na produção total. As médias de produção de tubérculos da classe 2 foram 39,54 e $34,82 \mathrm{t} / \mathrm{ha}$, com o uso de fungicidas contendo ou não zinco, respectivamente. $\mathrm{O}$ número de tubérculos das classes $2,3 \mathrm{e}$ 4 não foram significativamente afetados pelos tratamentos, mostrando que o efeito da pulverização com fungicidas contendo $\mathrm{Zn}$ influenciou apenas o peso dos tubérculos.

Em nenhuma classe foram observados tubérculos com rachaduras, embonecamento, coração oco e esverdeamento. $\mathrm{O}$ uso de fungicidas contendo $\mathrm{Zn}$ reduziu o teor de matéria seca dos tubérculos, sendo obtidos os valores de $15,4 \%$ e $16,0 \%$ para os tratamentos com fungicidas contendo ou não zinco, res- 
pectivamente. Estes valores estão próximos aos 16,4 e $15,7 \%$ de matéria seca encontrados por Rocha (1995) e Fontes et al. (1987) para outras cultivares. Por outro lado, o modo de aplicação do fertilizante não afetou os teores de matéria seca dos tubérculos.

\section{LITERATURA CITADA}

BEUKEMA, H.P.; VAN DER ZAAG, D.E. Introduction to potato production. Wageningen: Pudoc, 1990. 208 p.

BOAWN, L.C.; LEGGETT, G.E. Zinc deficiency of the Russet Burbank potato. Soil Science, v. 95, n. 1, p. 137-141, 1963.

BOAWN, L.C.; LEGGETT, G.E. Phosphorus and zinc concentrations in Russet Burbank potato tissues in relation to development of zinc deficiency symptoms. Soil Science Society Proceedings, v. 28, n. 1, p. 229-232, 1964.

CAKMAK, I.; MARSCHNER, H. Mechanism of phosphorus-induced zinc deficiency in cotton. III. Changes in physiological availability of zinc in plants. Physiology Plantarum, v. 70, n. 1, p.13-20, 1987.

CHRISTENSEN, N.W.; JACKSON, T.L. Potential for phosphorus toxicity in zinc stressed corn and potato. Soil Science Society of America, v. 45, n. 5, p. 904-909, 1981.

DUFFY, B.K.; DEFAGO, G. Zinc improves biocontrol of fusarium crown and root rot of tomato by pseudomonas fluorescens and represses the production of pathogen metabolites inhibitory to bacterial antibiotic biosynthesis. Phytopathology, v. 87, n. 12, p. 1250-1257, 1997.

ELLIS, N.K. Effect of zinc sulphate added to copperlime spray on the yield of potatoes on Indiana muck soil. Soil Science Society of America Proceedings, v. 9, n. 4, p. 131-132, 1945.

FAO. PRODUCTION YEARBOOK. Roma, v. 50, 1996. $325 \mathrm{p}$.

FONTES, P.C.R.; PAULA, M.B.; MIZUBUTI, A. Produtividade da batata sob influência de níveis do fertilizante 4-14-8 e do superfosfato simples. Revista Ceres, Viçosa, v. 34, n. 191, p. 90-98, 1987.

FONTES, P.C.R. Nutrição mineral e adubação. In: REIFSCHNEIDER, F.J.B. coord. Produção de batata. Brasília: Linha Gráfica Editora, 1987. p. $40-56$.
FONTES, P.C.R.; MASCARENHAS, M.H.T.; FINGER, F.L. Densidade de plantio da batata em função do preço dos tubérculos e da cultivar. Horticultura Brasileira, Brasília, v. 13, n. 2, p. 184-187, 1995.

FONTES, P.C.R.; ROCHA, F.A.T.; MARTINEZ, H.E.P. Produção de máxima eficiência econômica da batata, em função da adubação fosfatada. Horticultura Brasileira, Brasília, v. 15, n. 2, p. 104-107, 1997.

FONTES, P.C.R.; MOREIRA, M.A.; FONTES, P.C.R.; CARDOSO, A.A. Effects of zinc fungicides and different zinc fertilizer application methods on soluble and total zinc in potato plant shoots. Communication Soil Science Plant Analysis, v. 30, n. 13 \& 14, p. 1847-1859, 1999.

GRAHAM, R.D.; WEBB, M.J. Micronutrients and disease resistance and tolerance in plants. In: MORTVEDT, J.J.; COX, F.R.; SHUMAN, L.M.; WELCH, R.M. eds. Micronutrients in agriculture. 2 ed. Madison: Soil Science Society of America, 1991. p. 329-370.

GRUNES, D.L.; BOAWN, L.C.; CARLSON, C.W.; VIETS JUNIOR, F.G. Zinc deficiency of corn and potato; as related to soil and plant analysis. Agronomy Journal, v. 53, n. 2, p. 6871, 1961.

HOYMAN, W.G. The effect of zinc-containing dusts and sprays on the yield of potatoes. American Potato Journal, v. 26, n. 1. p. 256263, 1949.

LeBLANC, P.V.; GUPTA, U.C.; CHRSTIE, B.R. Zinc nutrition of silage corn grown on acid podzols. Journal of Plant Nutrition, v. 20, n. 2 \& 3, p. 345-353, 1997.

MARSCHNER, H.; CAKMAK, I. Mechanism of phosphorus induced zinc deficiency in cotton. II. Evidence for impaired shoot control of phosphorus uptake and translocation under $\mathrm{Zn}$ deficiency. Physiology Plantarum, v. 68, p. 491-496. 1986.

MARSCHNER, H. Mineral nutrition of higher plants. London: Academic Press, 1995. 889 p.

MARTENS, D.C.; WESTERMAN, D.T. Fertilizer applications for correcting micronutrient deficiencies. In: MORTVEDT, J.J.; COX, F.R.; SHUMAN, L.M.; WELCH, R.M. eds. Micronutrients in agriculture. 2 ed. Madison: Soil Science Society of America, 1991. p. 549-592.

MARTIN, W.E.; MCLEAN, J.G.; QUICK, J. Effect of temperature on the occurrence of phosphorus induced zinc deficiency. Soil Science Society America Proceedings, v. 29, n. 4, p. 411-413, 1965.
MOREIRA, M.A. Composição mineral e produção da batateira, em função do uso de fungicidas contendo ou não Zn e do modo de fertilização com Zn. Viçosa, MG: UFV, 1998. 88 p. (Tese mestrado), Universidade Federal de Viçosa, 1995.

MORENA, I.; GUILLEN, A.; MORAL, L.F.G. Yield development in potatoes as influenced by cultivars and the timing and level of nitrogen fertilization. American Potato Journal, v. 71, n. 3, p. 165-173, 1994.

PARKER, D.R. Responses of six crop species to solution zinc $^{2+}$ activities buffered with HEDTA. Soil Science Society American Journal, v. 61, p. 167-176. 1997.

PAULA, M.B.; FONTES, P.C.R.; NOGUEIRA, F.D. Absorção de micronutrientes por cultivares de batata em presença e ausência de adubação. Horticultura brasileira, Brasília, v. 4, n. 2, p. 3-8, 1986a.

REIS JR, R. dos A. Produção, qualidade de tubérculos e teores de potássio no solo e no peciolo de batateira em resposta à adubação potássica. Viçosa: UFV, 1995. 108 p. (Tese mestrado).

ROCHA, F.A.T. Crescimento, produção e qualidade de tubérculos de batata em função da fertilização fosfatada. Viçosa: UFV, 1995. 77 p. (Tese mestrado).

RODRIGUES, L.A.; SOUZA, A.P.; MARTINEZ, H.E.P.; PEREIRA, P.R.G.; FONTES, P.C.R. Absorção e translocação de zinco em feijoeiro aplicado via foliar. Revista Brasileira Fisiologia Vegetal, Brasília, v. 9, n. 2, p. 111-115, 1997.

VOLKWEISS, S.J. Fontes e métodos de aplicação. In: FERREIRA, M.E., CASTELLANE, P.D., CRUZ, M.C.P. eds. Micronutrientes na agricultura. Piracicaba: Potafos, 1991. p. 391409.

SAEED, M.; FOX, R.L. Influence of phosphate fertilization on zinc adsorption by tropical soils. Soil Science Society of America Journal, v. 43, n. 4, p. 683-686, 1979.

YILMAZ, A.; EKIZ, H.; TORUN, B.; GULTEKIN, I.; KARANLIK, S.; BAGCI, S.A.; CAKMAK, I. Effect of different zinc application methods on grain yield and zinc concentration in wheat cultivars grown on zinc-deficient calcareous soils. Journal of Plant Nutrition, v. 20, n. 4 \& 5, p. 461-471, 1997. 